\title{
STUDY ON ASYMPTOMATIC BACTERIURIA IN ELDERLY DIABETIC WOMEN
}

\author{
Dana Srinivasa Rao ${ }^{1}$, Beenaboina Venkata Ramana Murthy², Varikuti Aparna ${ }^{3}$, K. Suseela ${ }^{4}$, T. Geethanjali ${ }^{5}$ \\ 1Professor, Department of General Medicine, ACSR Government Medical College, Nellore, Andhra Pradesh. \\ ${ }_{2}^{2}$ Assistant Professor, Department of General Medicine, ACSR Government Medical College, Nellore, Andhra Pradesh. \\ ${ }^{3}$ Assistant Professor, Department of Pulmonology, ACSR Government Medical College, Nellore, Andhra Pradesh. \\ ${ }^{4}$ Assistant Professor, Department of Obstetrics and Gynaecology, ACSR Government Medical College, Nellore, Andhra Pradesh. \\ ${ }^{5}$ Assistant Professor, Department of Microbiology, ACSR Government Medical College, Nellore, Andhra Pradesh.
}

ABSTRACT

\section{BACKGROUND}

Prevalence of diabetes mellitus and asymptomatic bacteriuria is increasing drastically in developing countries, particularly in India. In the present study, an attempt has been made to find an association of the asymptomatic bacteriuria and diabetes mellitus type 2 .

The aim of this study is to estimate the prevalence of asymptomatic bacteriuria in elderly diabetic women. To assess if obstructive uropathy/ diabetic cystopathy has an association with asymptomatic bacteriuria in older diabetic women. To assess if other clinical and laboratory factors such as HbA1C, duration of diabetes, body mass index, etc. have an association with asymptomatic bacteriuria.

\section{MATERIALS AND METHODS}

107 older diabetic women who satisfied the inclusion criteria were recruited from the outpatient clinics of the Department of Medicine and the Department of Obstetrics and Gynaecology of the ACSR Govt. Medical College, Nellore, AP.

\section{RESULTS}

All of them were evaluated for diabetic comorbidities and complications- both microvascular and macrovascular. Of these 78 patients had given urine for culture to look for asymptomatic bacteriuria. Among them 61 went on to do the uroflowmetry to look for evidence of obstructive uropathy. Only 57 completed the post-void residual urine estimation, which was to look for diabetic cystopathy.

\section{CONCLUSION}

A total of 107 older diabetic women were screened for the study, of which 78 followed up to do the urine cultures; 13 prevalence of asymptomatic bacteriuria (ASB) was $16.7 \%$ (13 out of 78 ).

\section{KEYWORDS}

Diabetes Mellitus, Asymptomatic Bacteriuria (ASB).

HOW TO CITE THIS ARTICLE: Rao DS, Murthy BVR, Aparna V, et al. Study on asymptomatic bacteriuria in elderly diabetic women. J. Evolution Med. Dent. Sci. 2017;6(67):4793-4797, DOI: 10.14260/Jemds/2017/1039

\section{BACKGROUND Diabetic women have a higher prevalence of \\ India has become "the diabetes capital of the world ${ }^{1}$ and diabetes and its attendant complications are on the increase. Diabetic patients have an increased risk of getting infections, especially urinary tract infections and asymptomatic bacteriuria is one of the leading forerunners to urinary tract infection. ${ }^{2}$ \\ The general recommendation is that asymptomatic bacteriuria is not to be treated ${ }^{3,4}$ and that screening for this asymptomatic bacteriuria as compared to men and the prevalence has been found to increase with age. Most of the studies done on this condition have been in Europe and North America, and there are hardly any studies reported from India looking at the prevalence and associated risk factors for asymptomatic bacteriuria in the elderly diabetic population. The Figure 1 below shows the estimated number of diabetic subjects in India.5,6} condition and its treatment is necessary only in pregnant women and people undergoing urethral procedures with a risk of mucosal injury. There are studies which show people with asymptomatic bacteriuria have a higher risk for subsequent urosepsis.

Financial or Other, Competing Interest: None.

Submission 14-07-2017, Peer Review 10-08-2017,

Acceptance 16-08-2017, Published 21-08-2017.

Corresponding Author:

Beenaboina Venkata Ramana Murthy,

S/o. Beenaboina Subba Rao,

Flat No. 201, Teaching Staff Quarters

Government General Hospital,

Nellore, Andhra Pradesh.

E-mail: drmurthy26@gmail.com

DOI: $10.14260 /$ jemds $/ 2017 / 1039$

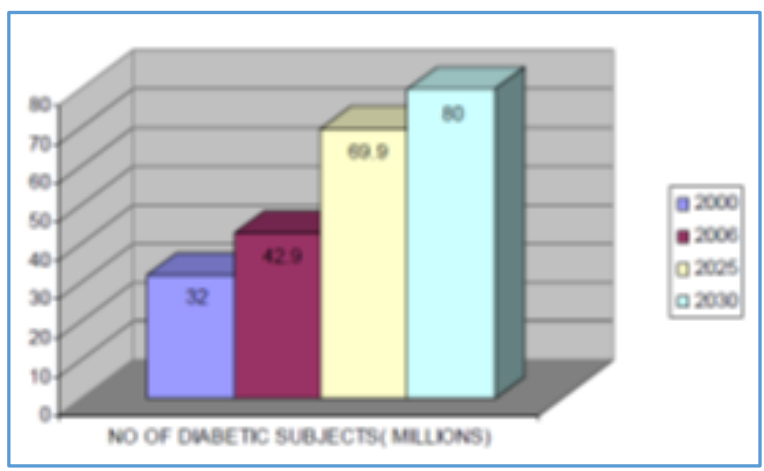

Figure 1. Indian Diabetic Population 
Patients with diabetes have an increased risk of urinary tract infections. There is a roughly five-fold greater propensity toward urinary tract infections in diabetic women. Urinary tract infections are likely to be more severe in diabetic than non-diabetic women in terms of the complications involved. Whether symptomatic urinary tract infections are preceded by asymptomatic bacteriuria (ASB) is a matter of debate.

Hence, this study was done among the diabetic outpatient population of a tertiary teaching care hospital in South India with a view of looking at potentially modifiable risk factors including cystopathy and bladder outlet obstruction to reduce the overall risk posed by this condition.

\section{MATERIALS AND METHODS}

\section{Setting}

107 older diabetic women who satisfied the inclusion criteria were recruited from the outpatient clinics of the Department of Medicine and the Department of Obstetrics and Gynaecology, ACSR Govt. Medical College Hospital, Nellore.

\section{Inclusion Criteria}

Female subjects were included in the study if they were ambulant, had type 2 diabetes mellitus, were above 50 years of age and gave written voluntary consent to take part in the study.

\section{Exclusion Criteria}

1. Patients with features of lower urinary tract infection (i.e. dysuria with increased frequency or dysuria with urgency or dysuria with fever) were excluded.

2. Patients who were on any antibiotics in the preceding two weeks prior to giving the urine sample were excluded.

3. Subjects who were unwilling to participate voluntarily were excluded.

\section{Study Design}

The study was a cross-sectional descriptive study on asymptomatic bacteriuria in elderly diabetic women attending the Medicine Clinic or Endocrine Clinic in our centre.

\section{Sample Size}

Sample size [n] for this descriptive study was calculated by using the following formula-

$\left[\mathrm{n}=4 \mathrm{pq} / \mathrm{d}^{2}\right]=4 \times 18 \times 82 / 8 \times 8=5904 / 64=92$.

Where $n=$ sample size, $p=$ prevalence in $\%, q=100-p, d=$ precision.

The desired sample size calculated with a precision of $8 \%$ was 92 older diabetic women assuming a prevalence of asymptomatic bacteriuria of $18 \%$ in elderly diabetic women.

\section{Study Protocol}

107 eligible subjects who satisfied inclusion criteria answered questions to provide the information to fill up a structured questionnaire regarding social, demographic and medical variables. The following features were looked into. The subjects were compared as regarding the presence of microvascular and macrovascular risk factors. They were also compared as for their physical indices and biochemical correlates. A separate questionnaire was used.
They then provided a midstream clean catch sample for purpose of doing urine culture. Those who gave the urine culture sample subsequently went and did uroflowmetry. They also got their post-void residual urine volume checked to look for any features of lower urinary tract obstruction or cystopathy.

\section{Uroflowmetry}

Uroflowmetry was measured by voiding into an uroflowmeter - Urodyn 1000 DANTEC Type 22 G02, which used an uroflow transducer from a rotating drum.

\section{Post-Void Residual Urine}

Post-void residue was measured by Merlin Ultrasound Model 1101 B-K medicals, which used the following formula to calculate the residual urine volume.

$\mathrm{V}=$ L.H.W.F

Where L= Length, $\mathrm{H}=$ Height, $\mathrm{W}=$ Width, $\mathrm{F}=$ Factor $(0.53$ for bladder).

\section{Urine Culture}

Urine was read for growth after incubating at 32 degrees Celsius for 24 hours on blood and MacConkey agar. The urine cultures that grew more than $10^{5}$ colonies/mL were considered as asymptomatic bacteriuria.

\section{Definitions}

The following were the cut-offs taken for defining the groups:

1. Definition of Diabetes Mellitus: - Diabetes was assumed for any patient who was on oral hypoglycaemic agents/ insulin or any subject fulfilling American Diabetic Association criteria for Diabetes mellitus. ${ }^{7}$ The diagnosis of diabetes was confirmed on a subsequent day by measuring any one of the three criteria. Fasting $>126$ $\mathrm{mg} \%$ (Fasting is defined as no calorie intake for at least 8 hours) or 2 hours postprandial glucose $>200 \mathrm{mg} \%$ or symptoms of diabetes plus random blood glucose $>200$ $\mathrm{mg} \%$.

2. Glycaemic Control: - HbA1c $<7$ - was taken as good control.

3. Body Mass Index: - Defined as,
a. Underweight if BMI was less than $18 \mathrm{~kg} / \mathrm{m} 2$
b. Normal if BMI was between 19 and $24 \mathrm{~kg} / \mathrm{m} 2$
c. Overweight if BMI was between 25 and $29 \mathrm{~kg} / \mathrm{m} 2$
d. Obese if BMI was more than $30 \mathrm{~kg} / \mathrm{m} 2$

4. Peripheral Neuropathy- Neuropathy was defined as per the International consensus meeting on the outpatient diagnosis and management of Diabetic neuropathy as "the presence of symptoms and/or signs of peripheral nerve dysfunction in people with diabetes after the exclusion of other causes."8

5. Nephropathy 9 - Microalbuminuria was present if the urine microalbumin was between 30 and 300 microgm $/ \mathrm{mg}$ of creatinine or $30-300 \mathrm{mg} /$ day in a 24-hour urine collection. Macroproteinuria- If urine microalbumin $>300$ microgm/mg of creatinine or 24-hour urine protein was more than $500 \mathrm{mg} / 24$ hours.

6. Renovascular Disease: - Any of the following features:

a. Renal bruit.

b. Doppler evidence of renal artery stenosis.

7. Obstructive Uropathy/ Cystopathy: - This was defined as per the standard urologic terminology of the International 
Continence Society guidelines. Abnormal post-void residual urine was defined as PVR more than $10 \%$ of the voided volume measured by ultrasound. Abnormal uroflowmetry was defined as the presence of peak urine flow less than $20 \mathrm{~mL} / \mathrm{sec}$ measured by an uroflowmeter.

8. Asymptomatic Bacteriuria: - Defined as the presence of at least 105 colony forming units/ $\mathrm{mL}$ of 1 or 2 of the same microorganism in a culture of clean voided midstream urine from a patient without fever or a symptom of urinary tract infection.

\section{Statistical Analysis of Data}

The prevalence of asymptomatic bacteriuria was calculated. Prevalence of diabetic cystopathy/ obstructive uropathy was calculated among those with and without asymptomatic bacteriuria. Analysis was done among the group with asymptomatic bacteriuria as compared with those without asymptomatic bacteriuria to calculate the odds ratio and 95\% $\mathrm{CI}$ for suspected risk factors like elevated $\mathrm{HbA1C}$, length of diabetes, presence of macrovascular complications, past history of urinary tract infection, etc. Univariate analysis of individual risk factors was performed for the final analysis and chi-square test was also done. The statistical software SPSS 16.0 for Windows was used for statistical calculations.

\section{RESULTS}

A total of 107 diabetic women patients were evaluated for the prevalence of asymptomatic bacteriuria. All were diabetics who attended the obstetrics and gynaecology outpatient clinic or the medicine outpatient clinic at the ACSR Govt. Medical College Hospital, Nellore. Of these, 78 patients had given urine for culture to look for asymptomatic bacteriuria. Among them, 61 went on to do the uroflowmetry to look for evidence of obstructive uropathy. Only 57 completed the post-void residual urine estimation, which was to look for diabetic cystopathy.

Duration of Diabetes (Years)- The duration of diabetes ranged from 0.25 years to 30 years with a mean duration of 10.08 years $(+/-7.64)$.

HbA1C- The HbA1C ranged between 6 gm\% and 13 gm\% with a mean of $8.24 \mathrm{gm} \%(+/-1.56), 14.3 \%$ (9 out of 63 ) of the subjects had an $\mathrm{HbA1C}$, which was $<7 \mathrm{gm} \%$ indicating good glycaemic control; $15.9 \%$ (10 out of 63 ) of the subjects had a poor glycaemic control with $\mathrm{HbA} 1 \mathrm{C}$ of $=/>10 \mathrm{gm} \%$. The breakdown of the HbA1C among those with asymptomatic bacteriuria is given in the table below.

\begin{tabular}{|c|c|c|}
\hline \multirow{2}{*}{ HbA1c } & Significant Urine Culture \\
\cline { 2 - 3 } & Absent & Present \\
\hline$<7 \mathrm{gm} \%$ & $8(15.4 \%)$ & $1(9.1 \%)$ \\
\hline $7-9.99 \mathrm{gm} \%$ & $38(73.1 \%)$ & $6(54.5 \%)$ \\
\hline$>9.99 \mathrm{gm} \%$ & $6(11.5 \%)$ & $4(36.4 \%)$ \\
\hline \multicolumn{3}{|c|}{ Table 1 } \\
\hline
\end{tabular}

The HbA1C levels and the risk of developing ASB was not significant (Fisher's Exact Test $=0.135$ ).

\section{BMI (Kg/M2)}

The BMI ranged from 16.8 to $34.2 \mathrm{~kg} / \mathrm{m} 2$. The mean BMI was $26.10 \mathrm{~kg} / \mathrm{m} 2$ (+/- 1.70); $34 \%$ (25) of the subjects had a BMI between $19-25 \mathrm{~kg} / \mathrm{m} 2 ; 4 \%$ (3) of the subjects were underweight; $47 \%$ (35) of the subjects were overweight; $15 \%$ (11) of the subjects were obese.

\section{Urinary Cultures Positive for Asymptomatic Bacteriuria}

The prevalence of asymptomatic bacteriuria detected was $16.7 \%$ (13 out of 78 ).

The commonest organism isolated was Escherichia coli among the 13 people with significant growth on urine culture (asymptomatic bacteriuria). Of them Escherichia coli was 84\% (11), Proteus 8\% (1) and Citrobacter diversus 8\% (1).

The prevalence of abnormal post-void residue was $36.4 \%$ among those with asymptomatic bacteriuria (4 out of 11). There was no significant correlation (Odds ratio $=0.329$ ) among the presence of bladder residue and ASB.

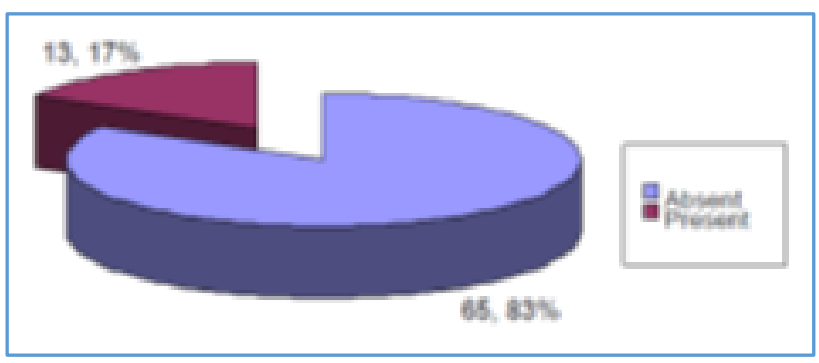

Figure 2. Prevalence of Asymptomatic Bacteriuria

\section{DISCUSSION}

A total of 107 older diabetic women were screened for the study, of which 78 followed up to do the urine cultures; 13 patients had significant urine cultures with colony counts greater than $10^{5}$ colonies $/ \mathrm{mL}$. The overall prevalence of asymptomatic bacteriuria (ASB) was $16.7 \%$, (13 out of 78 ). This prevalence of ASB was similar to what was described by Bonadio et al in 2004.10

Geerlings et al in 2000 reported a prevalence of $26 \%$. Our study was thus similar to earlier studies of diabetic women with the prevalence ranging from $8-26 \% .11,12$

Diabetic subjects taking insulin had 5.87 times higher odds of developing ASB as compared to those not on insulin. This was statistically significant $(95 \% \mathrm{CI}=1.61-21.5)$. This finding is similar to what was found by Bokyo et al in 2005 . Women taking insulin were mainly at higher risk, possibly because of more severe diabetes since the use of insulin may be a marker of disease severity. ${ }^{13}$

Subjects with macrovascular complications had 4.2 higher odds of developing ASB as compared to diabetic women without macrovascular complications. This result was statistically significant (95\%, CI 1.011 - 18.260).

Prevalence of abnormal Q-max during uroflowmetry among those with asymptomatic bacteriuria was $70 \%$ (7 out of 10). Diabetic subjects with a lower peak urinary flow rates (Q-max), especially $<10 \mathrm{~mL} / \mathrm{sec}$ had 1.154 times greater risk estimate of having asymptomatic bacteriuria as compared with those with Q-max $>20 \mathrm{~mL} / \mathrm{sec}$. This result was statistically significant $(95 \%, \mathrm{CI}=1.003-1.328)$. This could probably be indicative of a greater amount of bladder dysfunction, which is a long-term complication of asymptomatic bacteriuria and diabetes.

Diabetic subjects with retinopathy had 4.3 times the odds of developing ASB as compared to subjects without retinopathy. This figure was almost reaching statistical significance $(95 \%, \mathrm{CI}=0.944-19.58)$. 
Diabetic subjects with dyslipidaemia had 2.5 times greater risk of developing ASB as compared to diabetics with no dyslipidaemia. This was however not statistically significant $(95 \%, \mathrm{CI}=0.46$ - 60.797).

Diabetic subjects with abnormal serum creatinine had 2.5 times greater risk for developing ASB as compared to diabetics with normal serum creatinine. This was however not statistically significant $(95 \%, \mathrm{CI}=0.29-86.128)$. This was unlike what Ishay A et al described in 2006, who found serum creatinine as an independent risk factor for ASB. ${ }^{14}$

Diabetic patients with Nephropathy had 3.5 times risk of getting ASB as compared with patients who had no nephropathy. However, this figure was not statistically significant (95\%, CI = .681 - 18.387).

Some studies have shown that a longer duration of diabetes increases the risk of developing ASB, ${ }^{15}$ while others could not confirm this notion. In our study, duration of diabetes greater than 10 years as compared to those with diabetes duration less than 5 years showed a 2.3 times greater risk estimate, which was not statistically significant (95\%, CI= $0.447-12.571)$.

There was 5.33 times higher odds of patients with $\mathrm{HbA1c}$ $>10 \mathrm{gm} \%$ as compared to patients with an HbA1c $<7 \mathrm{gm} \%$ having asymptomatic bacteriuria, which was not statistically significant $(95 \%, \mathrm{CI}=0.46-60.797)$. This is similar to most studies but not all, which have found no relationship between glycaemic control and ASB.

A variety of potential ASB risk factors have been assessed in previous, mostly small-scale studies with inconsistent results. In these studies, there was no significant association for ASB with microvascular complications, vascular complications, heart disease, past history of urinary tract infection, past catheterisation, urinary incontinence and renal stones.

Though age is a well-known risk factor for bacteriuria in women without diabetes and some studies have shown age as the most important risk factor for ASB in type 2 diabetes mellitus, age had no significant relationship with ASB in our study (Odds $=1.22$ with $95 \% \mathrm{CI}=0.36-4.18$ ).

In our study, Body Mass Index (BMI) was not associated with any significant association with ASB (Odds ratio= 1.26 with $95 \%$ CI was 0.34 - 4.65). However, Geerling et al has proposed a low BMI as a risk factor for ASB.

Chronic complications such as nephropathy and neuropathy have been associated with ASB in type 1 but not with type 2 diabetic patients, a pattern that also holds for longer diabetes duration. In some of these studies, a small sample size and restricted number of variables limit the conclusions that could be drawn. We found no significant association between the occurrence of nephropathy or neuropathy and development of ASB.

The prevalence of abnormal post-void residue was $36.4 \%$ among those with asymptomatic bacteriuria (4 out of 11). There was no significant correlation (Odds ratio $=0.329$ ) among the presence of bladder residue and ASB. As found in other studies, the presence of peripheral neuropathy did not correlate significantly with bladder residue and ASB. 16

We diagnosed ASB using a single urine culture, as it was the most practical and cost-effective way to screen patients routinely. Although, the definition of ASB in women conventionally requires two urine cultures taken $>24$ hours apart, this practice does not improve specificity compared with a single specimen collection.

The commonest organism isolated was Escherichia coli (84\%) among the 13 women with significant growth on urine culture (Asymptomatic bacteriuria). The organism was similar to most other studies. The other organisms were Proteus 8\% (1) and Citrobacter diversus 8\% (1).

As there is a higher risk of ASB and acute symptomatic urinary tract infections (UTIs) among post-menopausal women $^{17}$ with diabetes, further adequately powered multicentre intervention studies are therefore needed to determine whether active screening for and prompt antibiotic treatment of ASB in diabetes is effective to reduce the risk of morbidity from UTIs.

\section{Limitations}

1. One of the drawbacks of the study was the small sample size, which would limit the statistical significance of individual risk factors. Multivariate analysis for comparing significant risk factors was not done in view of the small sample size.

2. Only a single urine culture was used in diagnosing asymptomatic bacteriuria due to financial constraints.

3. Community studies would be required with representative women to fully generalise the results to the rest of the community population, as the sample population was mainly diabetic women who presented to this tertiary care teaching hospital from the Nellore district of Andhra Pradesh.

4. The exact onset of Diabetes cannot be easily determined, since symptoms may remain occult for years. Error in estimating diabetes duration due to this problem is likely to underestimate the associated effects.

5. Due to ethical issues, we did not do invasive cystometrogram based pressure flow studies of the people who had significantly abnormal uroflowmetry and post-void residual urine abnormal results, which could help truly confirm obstructive uropathy and true detrusor dysfunction.

6. Presence of autonomic neuropathy other than postural drop in blood pressure was not measured.

\section{CONCLUSION}

1. Asymptomatic bacteriuria is a common finding in adults and diabetic women have a higher prevalence of this condition.

2. In our study, the prevalence of asymptomatic bacteriuria was $16.7 \%$.

3. There was no significant association between the occurrence of post-voidal residual urine (PVR) and asymptomatic bacteriuria.

4. Presence of macrovascular complications and the usage of insulin had a significantly increased risk of having asymptomatic bacteriuria.

\section{REFERENCES}

[1] Mohan V, Sandeep S, Deepa R, et al. Epidemiology of type 2 diabetes: Indian scenario. Indian J Med Res 2007;125(3):217-30. 
[2] Hooton TM, Scholees D, Stapleton AE, et al. A prospective study of asymptomatic bacteriuria in sexually active young women. $\mathrm{N}$ Engl J Med 2000;343:992-7.

[3] Harding GK, Zhanel GG, Nicolle LE, et al. Antimicrobial treatment in diabetic women with asymptomatic bacteriuria. N Engl J Med 2002;347(20):1576-83.

[4] Zhanel GG, Harding GK, Nicolle LE. Asymptomatic bacteriuria in patients with diabetes mellitus. Rev Infect Dis 1991;13(1):150-4.

[5] Wild S, Roglic G, Green A, et al. Global prevalence of diabetes: estimates for the year 2000 and projections for 2030. Diabetes Care 2004;27(5):1047-53.

[6] Sicree R, Shaw J, Zimmet P. Diabetes and impaired glucose tolerance. In: Gan D, (edr). Diabetes atlas. International diabetes federation. $3^{\text {rd }}$ edn. Belgium: International Diabetes Federation 2006:15-103.

[7] Balasubramanyam M, Mohan V. Diabetes in 2007what are the promises \& challenges? Indian J Med Res 2007;125:195-9.

[8] Association AD. Standards of medical care in diabetes2007. Diabetes Care 2007;30(Suppl 1):S4-41.

[9] Kaplan SA, Blaivas JG. Diabetic cystopathy. J Diab Complicat 1988;2(3):133-9.

[10] Bonadio M, Boldrini E, Forotti G, et al. Asymptomatic bacteriuria in women with diabetes: influence of metabolic control. Clin Infect Dis 2004;38(6):e41-5.
[11] Stapleton A. Urinary tract infections in patients with diabetes. Am J Med 2002;113(Suppl 1A):80S-4.

[12] Harris MI, Klein R, Welborn TA, et al. Onset of NIDDM occurs at least 4-7 years before clinical diagnosis. Diabetes Care 1992;15(7):815-9.

[13] Turner RC, Cull CA, Frighi V, et al. Glycaemic control with diet, sulfonylurea, metformin, or insulin in patients with type 2 diabetes mellitus: progressive requirement for multiple therapies. UK prospective diabetes study group. JAMA 1999;281(21):2005-12.

[14] Ishay A, Lavi I, Luboshitzky R. Prevalence and risk factors for asymptomatic bacteriuria in women with type 2 diabetes mellitus. Diabet Med 2006;23(2):1858.

[15] Zhanel GG, Nicolle LE, Harding GK. Prevalence of asymptomatic bacteriuria and associated host factors in women with diabetes mellitus. The manitoba diabetic urinary infection study group. Clin Infect Dis 1995;21(2):316-22.

[16] Geerlings SE, Stolk RP, Camps MJ, et al. Asymptomatic bacteriuria may be considered a complication in women with diabetes. Diabetes mellitus women asymptomatic bacteriuria utrecht study group. Diabetes Care 2000;23(6):744-9.

[17] Boyko, EJ, Fihn SD, Scholes D, et al. Risk of urinary tract infection and asymptomatic bacteriuria among diabetic and nondiabetic postmenopausal women. Am J Epidemiol 2005;161(6):557-64. 